\title{
Charif Majdalani, Caravansérail
}

\section{Veronica Amadessi}

\section{Q OpenEdition}

\section{Journals}

\section{Édition électronique}

URL : http://journals.openedition.org/studifrancesi/8400

DOI : 10.4000/studifrancesi.8400

ISSN : 2427-5856

\section{Éditeur}

Rosenberg \& Sellier

\section{Édition imprimée}

Date de publication : 1 mai 2009

Pagination : 218

ISSN : 0039-2944

\section{Référence électronique}

Veronica Amadessi, « Charif Majdalani, Caravansérail », Studi Francesi [En ligne], 157 (LIII | I) | 2009, mis en ligne le 30 novembre 2015, consulté le 11 janvier 2021. URL : http://journals.openedition.org/ studifrancesi/8400 ; DOI : https://doi.org/10.4000/studifrancesi.8400

\section{Ce document a été généré automatiquement le 11 janvier 2021.}

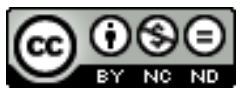

Studi Francesi è distribuita con Licenza Creative Commons Attribuzione - Non commerciale - Non opere derivate 4.0 Internazionale. 


\title{
Charif Majdalani, Caravansérail
}

\author{
Veronica Amadessi
}

\section{RÉFÉRENCE}

CHARIF MAJDALANI, Caravansérail, Paris, Seuil, 2007, pp. 214.

1 Le deuxième roman de Charif Majdalani, sélectionné pour le Prix Renaudot et pour le Prix Médicis, est une aventure rocambolesque à travers déserts et savanes, où le personnage principal, Samuel Ayyad, achète un palais en pièces détachées pour le transporter jusqu'au Liban, sa terre natale. Samuel est un jeune érudit libanais, anglophone et protestant. Grâce à ces atouts, il est engagé en tant qu'officier civil par les forces anglo-égyptiennes qui gouvernent le Soudan au début $d u x^{e}$ siècle. La narration commence donc par le départ du personnage de son pays. Le voyage s'avère de plus en plus aventureux, se déroulant à travers l'Afrique, la Syrie, l'Arabie. Il s'agit d'une véritable odyssée au cours de laquelle le héros, suivi du cortège qui transporte son palais, croise des soldats ottomans, des sultans, des troupes anglaises... L'«odyssée tordue» de Samuel, comme le narrateur se plait à la définir, a tout d'une errance fantastique, c'est l'histoire d'un émigré mais aussi du sérail atypique qu'il emmène avec lui. En effet, il n'est pas seulement question de l'errance d'un homme, mais aussi de l'errance d'un objet, le palais, qui devient donc un élément essentiel caractérisant le personnage. Dans le récit, le romancier fait souvent recours à des comparaisons pour décrire Samuel et son étrange caravane, le caravansérail qui donne son nom au titre et qui serait, d'après l'explication amusée du narrateur, «un sérail sur caravane». Tous les traits de la narration contribuent à souligner l'attachement de l'auteur à l'idée de «mélanges»: en effet, issu lui-même d'un mariage mixte, il mêle sciemment les références culturelles tout en les brouillant. Voilà alors qu'il présente un personnage extra-ordinaire, parlant trois langues et s'adaptant à tout milieu et à toute société; ou encore, un objet, le palais, maison arabo-islamique, démontée et déplacée par deux Libanais chrétiens. Les peuples et les cultures semblent se mélanger en une fresque réunissant tous les contraires. Ce qui frappe le plus dans ce roman est sans doute son style percutant, qui alterne de longues périodes à de brèves sentences; un style qui se 
propose à la fois de construire un récit et de dire la façon dont ce récit se construit, en d'autres termes, de «raconter une histoire et [de] montrer comme on la raconte». Après le succès de son premier roman, qui avait pour objet la naissance d'un clan familial, Majdalani brosse ici le portrait d'un héros nomade, au croisement de plusieurs codes culturels, et d'une demeure en morceaux reconstituée par des érudits chrétiens, probable métaphore de la renaissance des lettres arabes. Récit de l'errance aux tons presque épiques, cette odyssée moderne nous fascine grâce à son style et à son rythme de «chevauchées sous de grandes bannières jetées dans le vent». 